\title{
RISK FACTORS FOR DEEP STERNAL WOUND INFECTION AFTER STERNOTOMY: A PROSPECTIVE, MULTICENTER STUDY
}

The Parisian Mediastinitis Study Group*

\begin{abstract}
Several risk factors for deep sternal wound infection after sternotomy remain unclear. To assess and compare risk factors among units, a prospective study included 1830 patients in 10 units during a 4-month period: 960 underwent coronary artery bypass grafting and 870 underwent other procedures. According to the Centers for Disease Control and Prevention definitions, $2.3 \%$ of patients $(42 / 1830)$ acquired a deep sternal wound infection. Independent risk factors for deep sternal wound infection were obesity, coronary artery bypass grafting, reoperation, and postoperative inotropic support. Independent risk factors after coronary artery bypass grafting were obesity, bilateral internal thoracic artery grafting, reoperation, and postoperative inotropic support. In all five of the units usually performing bilateral internal thoracic artery graftings, this procedure was associated with high risk of deep sternal wound infection. Duration of operation was a major risk factor in comparison of the unit with the highest risk of deep sternal wound infection with the other nine units; this suggests that parameters related to the perioperative period were involved. Multicenter surveillance is useful to determine reliable risk factors for deep sternal wound infection, to define a high-risk population before operation, and to assess unit-specific risk factors. ( $J$ Thorac Cardiovasc Surg 1996;111:1200-7)
\end{abstract}

$D^{\mathrm{e}}$ eep sternal wound infections (DSWIs) are rare, complicating $1 \%$ to $4 \%$ of sternotomies. Their consequences are severe, however, with high mortality, morbidity, and added hospital stay. ${ }^{1-3}$

Many studies have established risk factors for sternal wound infections (SWIs). Some parameters have been regularly associated with DSWI, such as obesity and reoperation. Other risk factors, such as the use of one or two internal thoracic arteries (ITAs) for coronary artery bypass grafting (CABG), age, duration of operation or complicated postoperative courses, have been associated with DSWI in some studies and not in others. Several causes may

From The Parisian Mediastinitis Study Group.

Received for publication June 13, 1995; accepted for publication August 1, 1995.

Address for reprints: Jean-Christophe Lucet, MD, MPH, Unité d'Hygiène et de Lutte contre l'Infection Nosocomiale, Hôpital Bichat-Claude Bernard, 46, Rue Henri Huchard, 75018 Paris, France.

"The Parisian Mediastinitis Study Group members are listed at the end of this article.

Copyright (c) 1996 by Mosby-Year Book, Inc.

$0022-5223 / 96 \$ 5.00+0 \quad \mathbf{1 2 / 1 / 6 8 3 9 3}$ account for these variable results. First, all of the studies involving a large number of patients have been retrospective. The accuracy of the parameters recorded and the quality of wound surveillance are therefore variable. Second, the endpoints differ among studies, with some studies pooling DSWIs with infections at other sites, superficial SWI, or sternal mechanical complications. More important, all these studies are from single centers. It is likely that selection of patients, choice of procedures, and management of the perioperative period vary greatly among cardiac surgical units. These parameters, although difficult to record, may be important determinants of DSWI. A prospective multicenter study was conducted with two purposes: to ascertain the incidence of DSWI and to identify high-risk patients or procedures.

\section{Methods}

Population and study variables. The study was conducted in 10 cardiac surgical units in the Paris area. Adults (aged at least 16 years) who underwent sternotomy between March 8 and July 4, 1993, and were followed up for at least 8 days after sternotomy were considered eligible. Patients who died before the postoperative day 8 were not included in the evaluation. 


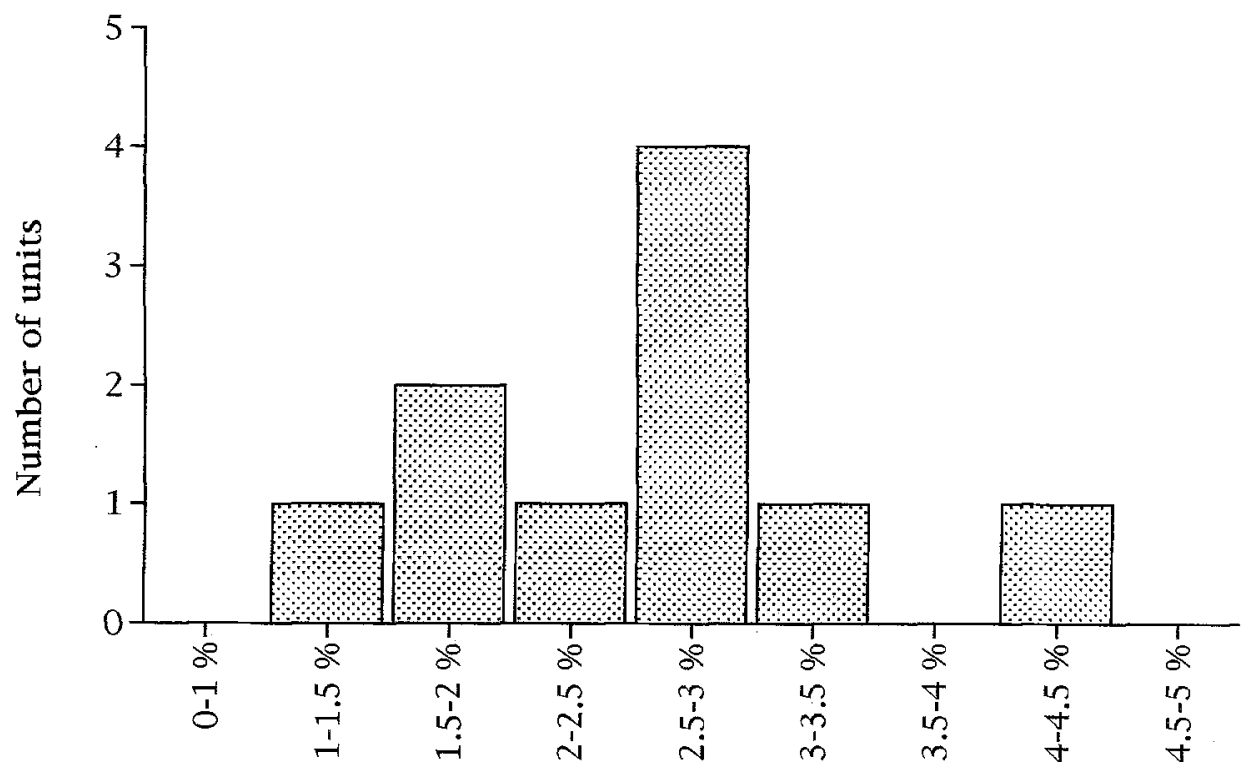

Risk of deep sternal wound infection

Fig. 1. Distribution by unit of DSWI risk.

The following baseline characteristics were recorded: age, sex, diabetes (medication with an antidiabetic drug), heart failure as defined by the New York Heart Association score, obesity as defined by the body mass index (weight in kilograms divided by the square of height in meters), previous sternotomy, antimicrobial therapy within 10 days before operation, entering the cardiac surgical unit from an intensive care unit (ICU), and duration of preoperative stay in the cardiac surgical unit. Perioperative parameters included hair removal (no preparation versus clipping, shaving, or depilation of the operative site), preoperative severity of illness assessment as defined by the American Society of Anesthesiologists score ${ }^{4}$ emergency operation, type of operation (CABG, valvular repair, other), number of ITAs used for grafting, operative (skin incision to skin closure) time, and bypass time. Postoperative variables included reoperation (within 15 postoperative days), duration of mechanical ventilation, and significant use of vasoactive agents (any dose of epinephrine or norepinephrine; isoprenaline $>0.1 \mathrm{gm}$. $\mathrm{kg}^{-1} \cdot \min ^{-1} ;$ dopamine, dobutamine, or enoximone $>10$ $\left.\mathrm{gm} \cdot \mathrm{kg}^{-1} \cdot \min ^{-1}\right)$.

Definitions of infections. Surgical site definitions were those of the Centers for Disease Control and Prevention. ${ }^{5}$ Briefly, superficial SWI must involve only skin or subcutaneous tissue of the incision. In addition, superficial SWI must include at least one of the following: (1) purulent drainage is present; (2) an organism is isolated from the incision; (3) at least one of the following symptoms, tenderness, swelling, redness, or heat, is present and the incision is opened by a surgeon; or (4) diagnosis is made by the surgeon or attending physician. DSWI was defined to be infection involving tissues or spaces beneath the subcutaneous tissue. In addition, DSWI must fit at least one of the following criteria: (1) an organism is isolated from culture of mediastinal tissue or fluid; (2) evidence of mediastinitis is seen during operation or by histopathologic examination; or (3) one of the following, fever ( $>38^{\circ}$ C), chest pain, or sternal instability, is present and there is either purulent drainage from the mediastinum or an organism isolated from blood culture or culture of drainage of the mediastinal area. If organisms from common skin flora (coagulase-negative staphylococci, diphtheroids, Bacillus species, Propionibacterium species) were isolated, two positive cultures with the same strain were required. DSWI was categorized as osteomyelitis when infection was limited to the sternal bone and as mediastinitis when infection included the mediastinal area.

Surveillance. The sternal wound was assessed on a daily basis during the patient's stay in the cardiac surgical unit. If the patient was discharged before postoperative day 8 , surveillance was continued in the new location until at least that date. Cardiac surgical units were visited each week to ascertain completeness of sternal wound surveillance and description of infections. Operative logbooks were reviewed to ensure the inclusion of all patients and to identify all reoperations.

Statistical methods. Both univariate and multivariate techniques were used. Contingency tables were used for categoric variables. Unadjusted relative risks (RRs) were determined, $\chi^{2}$ test (or Fisher's Exact Test and $\chi^{2}$ test for linear trend when appropriate) was applied, and $95 \%$ confidence intervals $(95 \% \mathrm{CIs})$ were reported. For continuous variables, the mean \pm standard deviation was used to describe the data and Student's $t$ test or analysis of variance was used to compare values between groups. We next performed a stepwise multiple logistic regression analysis. All variables suggested by the univariate analysis 
Table I. Assessment of potential risk factors associated with DSWI in 1789 patients

\begin{tabular}{|c|c|c|c|c|c|c|c|}
\hline \multirow[b]{2}{*}{ Variables } & \multicolumn{2}{|c|}{$\begin{array}{l}\text { Patients without infection } \\
\qquad(n=1747)\end{array}$} & \multicolumn{2}{|c|}{$\begin{array}{l}\text { Patients with DSWI } \\
\qquad(n=42)\end{array}$} & \multirow[b]{2}{*}{ Relative risk } & \multirow[b]{2}{*}{$95 \% C I$} & \multirow[b]{2}{*}{$p^{*}$} \\
\hline & No. & $\%$ & No. & $\%$ & & & \\
\hline \multicolumn{8}{|l|}{ Preoperative variables } \\
\hline \multicolumn{8}{|l|}{ Age $(y r)$} \\
\hline$<45$ & 304 & 17.4 & 7 & 16.7 & 1.68 & $0.57-4.95$ & \\
\hline $45-54$ & 282 & 16.1 & 7 & 16.7 & 1.81 & $0.61-5.33$ & \\
\hline $55-64$ & 442 & 25.3 & 6 & 14.3 & 1.00 & - & $>0.25$ \\
\hline $65-74$ & 563 & 32.2 & 17 & 40.4 & 2.19 & $0.87-5.51$ & \\
\hline$\geq 75$ & 156 & 8.9 & 5 & 11.9 & 2.32 & $0.72-7.49$ & \\
\hline$\geq 65$ & 719 & 41.2 & 22 & 52.4 & 1.56 & $0.86-2.82$ & 0.14 \\
\hline$<65$ & 1028 & 58.8 & 20 & 47.6 & & & \\
\hline \multicolumn{8}{|l|}{ Gender } \\
\hline Male & 1219 & 69.8 & 36 & 85.7 & 2.55 & $1.12-5.82$ & 0.03 \\
\hline Female & 528 & 30.2 & 6 & 14.3 & & & \\
\hline \multicolumn{8}{|c|}{ Entering surgery unit from an ICU } \\
\hline Yes & 159 & 9.1 & 8 & 19.0 & 2.28 & $1.09-4.79$ & 0.03 \\
\hline No & 1588 & 90.9 & 34 & 81.0 & & & \\
\hline \multicolumn{8}{|l|}{ Obesity (body mass index) } \\
\hline$\geq 30$ & 170 & 9.7 & 10 & 23.8 & 2.79 & $1.43-5.47$ & 0.003 \\
\hline$<30$ & 1577 & 90.3 & 32 & 76.2 & & & \\
\hline \multicolumn{8}{|l|}{ NYHA score } \\
\hline$\geq 3$ & 742 & 42.5 & 15 & 35.7 & 0.75 & $0.40-1.41$ & $>0.25$ \\
\hline$<3$ & 1000 & 57.5 & 27 & 64.3 & & & \\
\hline \multicolumn{8}{|l|}{ Diabetes } \\
\hline Yes & 192 & 11.0 & 7 & 16.7 & 1.60 & $0.72-3.54$ & 0.25 \\
\hline No & 1555 & 89.0 & 35 & 83.3 & & & \\
\hline \multicolumn{8}{|l|}{ Previous sternotomy } \\
\hline Yes & 243 & 13.9 & 5 & 11.9 & 1.19 & $0.47-2.99$ & $>0.25$ \\
\hline No & 1504 & 86.1 & 37 & 88.1 & & & \\
\hline \multicolumn{8}{|l|}{ Antimicrobial therapy within } \\
\hline Yes & 179 & 10.2 & 4 & 9.5 & 0.92 & $0.33-2.56$ & $>0.25$ \\
\hline No & 1568 & 89.8 & 38 & 90.5 & & & \\
\hline \multicolumn{8}{|c|}{ Perioperative and postoperative variables } \\
\hline \multicolumn{8}{|c|}{ Type of operation } \\
\hline TCABG & 900 & 51.5 & 32 & 76.2 & 2.94 & $1.50-5.74$ & 0.002 \\
\hline Valvular repair or other & 847 & 48.5 & 10 & 23.8 & & & \\
\hline Hair removal (any type) & & & & & & & \\
\hline Yes & 1181 & 67.6 & 36 & 85.7 & 2.82 & $1.25-6.38$ & 0.01 \\
\hline No & 566 & 32.4 & 6 & 14.3 & & & \\
\hline Emergency operation & & & & & & & \\
\hline Yes & 178 & 10.2 & 6 & 14.3 & 1.45 & $0.62-3.40$ & $>0.25$ \\
\hline No & 1569 & 89.9 & 36 & 85.7 & & & \\
\hline ASA score & & & & & & & \\
\hline$\geq 3$ & 1347 & 77.1 & 35 & 83.3 & 1.47 & $0.66-3.29$ & $>0.25$ \\
\hline$<3$ & 400 & 22.9 & 7 & 16.7 & & & \\
\hline Duration of operation (min & & & & & & & \\
\hline$<180$ & 558 & 32.0 & 11 & 26.2 & 1.00 & - & \\
\hline $180-209$ & 385 & 22.0 & 6 & 14.3 & 0.79 & $0.30-2.13$ & \\
\hline $210-269$ & 489 & 28.0 & 14 & 33.3 & 1.44 & $0.66-3.14$ & 0.17 \\
\hline$\geq 270$ & 315 & 18.0 & 11 & 26.2 & 1.75 & $0.77-3.98$ & \\
\hline$\geq 200$ & 891 & 51.0 & 27 & 64.3 & 1.71 & $0.92-3.16$ & 0.09 \\
\hline$<200$ & 856 & 49.0 & 15 & 35.7 & & & \\
\hline Reoperation & & & & & & & \\
\hline Yes & 98 & 5.6 & 7 & 16.7 & 3.21 & $1.50-6.85$ & 0.003 \\
\hline No & 1649 & 94.4 & 35 & 83.3 & & & \\
\hline & & & & & & & ontinued \\
\hline
\end{tabular}


Table I. Continued

\begin{tabular}{|c|c|c|c|c|c|c|c|}
\hline \multirow[b]{2}{*}{ Variables } & \multicolumn{2}{|c|}{$\begin{array}{l}\text { Patients without infection } \\
\qquad(n=1747)\end{array}$} & \multicolumn{2}{|c|}{$\begin{array}{l}\text { Patients with DSWI } \\
\qquad(n=42)\end{array}$} & \multirow[b]{2}{*}{ Relative risk } & \multirow[b]{2}{*}{$95 \% \mathrm{CI}$} & \multirow[b]{2}{*}{$p^{*}$} \\
\hline & No. & $\%$ & No. & $\%$ & & & \\
\hline \multicolumn{8}{|l|}{ Inotropic agents } \\
\hline$\geq 24 \mathrm{hr}$ & 285 & 16.3 & 13 & 31.0 & 2.24 & $1.19-4.21$ & 0.01 \\
\hline$<24 \mathrm{hr}$ & 1462 & 83.7 & 29 & 69.0 & & & \\
\hline \multicolumn{8}{|c|}{ Mechanical ventilation } \\
\hline$\geq 24 \mathrm{hr}$ & 372 & 21.3 & 28 & 66.7 & 1.82 & $0.97-3.40$ & 0.06 \\
\hline$<24 \mathrm{hr}$ & 1375 & 78.7 & 14 & 33.3 & & & \\
\hline
\end{tabular}

Forty-one patients with superficial SWI were excluded from the analysis. ASA, American Society of Anesthesiologists; NYHA, New York Heart Association. ${ }^{*} p$ value by $\chi^{2}$ test, Fisher's Exact Test or $\chi^{2}$ test for linear trend.

$(p<0.25)$ were entered in the model after categorization of continuous variables, and PROC LOGISTIC (SAS Institute Inc., Cary, N.C.) was used to obtain maximum likelihood estimates. Stratified analysis was performed with the Mantel-Haenszel procedure and test-based 95\% CIs were reported. These analyses were performed with SAS software (SAS Institute). All tests were two-sided, with a $p$ value $<0.05$ considered significant.

\section{Results}

Global population. During the study period, 1891 adults were included; $56(3.0 \%)$ died and five were unavailable for follow-up within the first 7 days after operation. Of the 1830 eligible patients (38 to 298 patients per unit), 41 acquired a superficial SWI $(2.2 \%, 95 \% \mathrm{CI} 1.6 \%$ to $2.9 \%)$ and 42 acquired a DSWI $(2.3 \%, 95 \%$ CI $1.5 \%$ to $3.1 \%)$. Thirty DSWIs were considered to be mediastinitis and 12 were considered to be sternal osteomyelitis. Five (11.9\%) of the 42 patients with DSWI died. All patients with DSWI survived beyond postoperative day 8 . Further analysis focused on patients with DSWI. DSWI ratio among units ranged from $1.0 \%$ to $4.4 \%$ (Fig. 1). The time to DSWI after sternotomy was $13 \pm 6.7$ days (median 12 days, range 4 to 29 days). One or more microorganisms were isolated in 39 of the 42 DSWIs; these included Staphylococcus aureus (13 methicillin sensitive and 11 methicillin resistant), coagulase-negative staphylococci (three methicillin sensitive and four methicillin resistant), Enterococcus species (three), Streptococcus species (four), Serratia marcescens (two), Candida species (one), and Enterobacter cloacae (one).

We next compared 42 patients who had DSWI with 1747 patients without infection (Table I). The incidence of DSWI increased, although non significantly, at extreme ages. It was similar in patients with moderate obesity (body mass index 25 to 30 ) and without obesity. Obesity was therefore defined as a body mass index of at least 30 . Other preoperative risk factors were male sex and entering the cardiac surgical unit from an ICU. Duration of preoperative stay was similar in patients with and without DSWI (data not shown).

The risk of DSWI was higher after CABG alone or CABG combined with another procedure (3.3\% [29/876] and 3.6\% [3/84], respectively) than after valvular repair alone $(1.2 \%$ [9/751]) or other operations $(0.8 \%$ [1/119]). Surgical procedures were therefore pooled into two groups: $\mathrm{CABG}$ alone or combined, referred to as total CABG (TCABG), and other operations. Hair removal (any type) was a risk factor for DSWI, without differences between the three methods (data not shown). Bypass (data not shown) and operative times were similar in both groups of patients. Other risk factors were reoperation and significant use of inotropic support for at least 24 hours after operation. Independent risk factors for DSWI were obesity, TCABG, reoperation, and significant use of inotropic agents for at least 24 hours (Table II).

Type of operation and risk factors for DSWI. Multivariate analysis demonstrated the importance of TCABG as a risk factor for DSWI. In addition, previous studies disagreed about the infectious risk after bilateral ITA grafting. ${ }^{2,6-9}$ Further analysis was therefore conducted separately for patients with and without TCABG.

Patients with CABG. Of the 960 patients who underwent TCABG, $32(3.3 \%)$ acquired a DSWI. In univariate analysis, risk factors for DSWI were age younger than 45 years (RR 4.14,; $95 \% \mathrm{Cr} 1.22$ to $14.1, p=0.03$ ), obesity (RR $2.21,95 \%$ CI 1.03 to $4.76, p=0.04$ ), bilateral ITA grafting ( $\mathrm{RR} 4.78$, $95 \%$ CI 1.36 to $16.7, p=0.01$ ), reoperation (RR $4.02,95 \% \mathrm{CI}, 1.69$ to $9.57, p=0.002$ ), and significant use of inotropic agents for at least 24 hours 
Table II. Independent risk factors for DSWI after sternotomy (logistic regression analysis)

\begin{tabular}{|c|c|c|c|c|c|}
\hline Variables & Estimate & $S E$ & $O R$ & $95 \% \mathrm{Cl}$ & $p^{*}$ \\
\hline \multicolumn{6}{|l|}{ All patients $(n=1789)$} \\
\hline Obesity (body mass index $\geq 30$ ) & 0.98 & 0.38 & 2.67 & $1.27-6.00$ & 0.009 \\
\hline $\mathrm{TCABG}$ & 0.98 & 0.38 & 2.67 & $1.25-5.67$ & 0.01 \\
\hline Reoperation & 1.19 & 0.45 & 3.30 & $1.38-7.92$ & 0.007 \\
\hline Inotropic agents $\geq 24 \mathrm{hr}$ & 0.86 & 0.35 & 2.37 & $1.19-4.73$ & 0.01 \\
\hline \multicolumn{6}{|l|}{ Patients with TCABG $(n=932)$} \\
\hline Obesity (body mass index $\geq 30$ ) & 0.89 & 0.44 & 2.44 & $1.04-5.75$ & 0.04 \\
\hline Bilateral ITA grafting & 1.44 & 0.45 & 4.20 & $1.91-9.23$ & 0.0003 \\
\hline Reoperation & 1.32 & 0.54 & 3.73 & $1.29-10.8$ & 0.015 \\
\hline Inotropic agents $\geq 24$ hours & 0.90 & 0.43 & 2.45 & $1.06-5.67$ & 0.04 \\
\hline \multicolumn{6}{|l|}{ Patients without TCABG $(n=857)$} \\
\hline Age $\geq 75 \mathrm{yr}$ & 1.92 & 0.75 & 6.81 & $1.58-29.4$ & 0.01 \\
\hline Diabetes & 1.92 & 0.85 & 6.80 & $1.29-35.8$ & 0.02 \\
\hline Duration of operation $\geq 270$ min & 1.64 & 0.70 & 5.14 & $1.30-20.3$ & 0.02 \\
\hline
\end{tabular}

Forty-one patients with superficial SWI were excluded from analysis. SE, Standard error.

* $p$ value by Wald test.

(RR $2.33,95 \%$ CI 1.10 to $4.86, p=0.02$ ). Patients entering the cardiac surgical unit from an ICU (RR $2.16,95 \% \mathrm{CI} 0.97$ to $4.82, p=0.06$ ) or ventilated for at least 24 hours after operation (RR $1.82,95 \%$ CI 0.88 to $3.76, p=0.1$ ) had higher risk of DSWI, but these differences did not reach statistical significance.

The risk of DSWI after bilateral ITA grafting $(8.7 \%$ [11/126]) was higher than after TCABG without ITA $(1.9 \%$ [3/157]) or after unilateral ITA grafting $(2.7 \%[18 / 677])$, a significant difference between bilateral ITA grafting and the other two methods (RR $4.78,95 \%$ CI 1.36 to $16.7, p=0.006$, and RR 3.38, 95\% CI 1.64 to $17.0, p=0.002$, respectively). The risks of DSWI after unilateral ITA grafting and after TCABG without ITA were similar (RR $1.41,95 \%$ CI 0.42 to $4.74, p=0.6$ ).

Patients who underwent bilateral ITA grafting were compared with patients who underwent TCABG with one ITA or without ITA use. They were younger (mean 58.0, 63.2, and 67.5 years, respectively, $p<0.0001$ ) and had a longer duration of operation (mean 246, 209, and 222 minutes, respectively, $p<0.0001$ ). Rates of reoperation were similar in the three groups $(5.6 \%, 4.1 \%$, and $5.7 \%$, respectively). Independent risk factors for DSWI after TCABG were obesity, bilateral ITA grafting, reoperation, and significant use of inotropic support for at least 24 hours (Table II). Entering the cardiac surgical unit from an ICU was not an independent risk factor (odds ratio [OR] 2.26, 95\% CI 0.92 to $5.55, p=0.07)$. Referral from an ICU, however, was observed for six of 11 patients with DSWI after bilateral ITA grafting and five of 108 patients with- out infection after this procedure (RR $11.8,95 \% \mathrm{CI}$ 4.28 to $32.4, p<0.0001$ ).

Almost all bilateral ITA graftings (106/126) were performed in five units (16 to 31 procedures/unit) and almost all DSWIs (9/11) developed in these patients. In all five units, the risk of DSWI increased after CABG without ITAs, with one ITA, or with two ITAs $(0 / 10$ to $1 / 11,1 / 64$ to $3 / 70$, and $1 / 16$ to $3 / 19$, respectively). With respect to preoperative risk factors (obesity, referral from an ICU, and bilateral ITA grafting), the incidence of DSWI after TCABG increased from $2.2 \%(14 / 639)$ without any risk factors to $3.9 \%(11 / 282)$ with one risk factor and $17.9 \%$ $(7 / 39)$ with two $(6 / 37)$ or three $(1 / 2)$ risk factors.

Patients with valvular repair or operation other than $C A B G$. Eight hundred seventy patients underwent operation without CABG and 10 of these $(1.1 \%)$ acquired a DSWI. In univariate analysis, age of at least 75 years (RR 4.46, 95\% CI 1.31 to $15.2, p=$ 0.02 ) and diabetes (RR 4.98, 95\% CI 1.24 to $19.9, p$ $=0.02$ ) were risk factors for DSWI. A trend was observed for obesity (RR 3.44, 95\% CI 0.81 to 14.6 , $p=0.09)$, an operative time of at least 270 minutes (RR 3.41, 95\% CI 0.98 to $11.94, p=0.06$ ), and significant postoperative use of inotropic agents for at least 24 hours (RR 2.82, 95\% CI 0.85 to $9.39, p=$ 0.09). Independent risk factors for DSWI were age of at least 75 years, diabetes, and operative time of at least 270 minutes (Table II).

Unit-specific risk factors. Only one unit (unit A), which had the highest risk of DSWI, differed from the mean risk of the other nine units (RR 2.13,95\% CI 1.01 to $4.48, p=0.046$ ). When the multivariate model was revised to include each unit as a variable 
(comparing one unit with the other nine), patients operated on in unit $\mathrm{A}$ were twice as likely to acquire DSWI as patients in the other nine units (OR 2.10, $95 \%$ CI 0.94 to $4.72, p=0.07$ ). A separate analysis was therefore conducted for this unit. In univariate analysis, the occurrence of DSWI was associated with an operative time of at least 200 minutes (RR $11.6,95 \%$ CI 2.30 to $58.4, p=0.003$ ), and a trend was observed in patients undergoing TCABG (RR $5.77,95 \%$ CI 0.82 to $42.3, p=0.07$ ) or receiving significant postoperative inotropic support for at least 24 hours (RR 3.23, 95\% CI 0.90 to $11.7, p=$ $0.07)$. Independent risk factors for DSWI in unit A were emergency operation (OR 8.15, 95\% CI 1.20 to $55.5, p=0.03$ ), TCABG (OR $11.7,95 \% \mathrm{CI} 1.07$ to $127, p=0.04)$, and operative time of at least 200 minutes (OR 24.2, 95\% CI 2.25 to $259, p=0.009$ ).

In previous analyses, operative time was categorized with the threshold of 200 minutes. The variation in operative times for the same surgical procedure among units, however, might distort these results. To address this problem, deciles of operative times were defined for each unit. Risks of DSWI in each decile were compared for the entire population. The 70 th percentile was found to best discriminate across units between patients with and without DSWI (RR 1.97, 95\% CI 1.09 to $3.55, p=0.02$ ). With this threshold and after stratification by type of operation and use of ITA, the increased infectious risk in the higher operative time class (greater than 70th percentile) was entirely explained by patients operated on in unit A (RR 15.4; 95\% CI 2.96 to $80.6, p=0.0001$ in unit A, and RR $0.93,95 \%$ CI 0.46 to $1.85, p=0.8$ in the other nine units). Despite these data, however, unit A had the fourth lowest operative time defining the 70 th percentile among the 10 units (209 minutes).

\section{Discussion}

The first goal of this study was to assess the risk of DSWI after sternotomy across a large number of cardiac surgical units. The ratio of $2.3 \%$ is high compared with data from other studies. There may be several explanations for these findings. First, in several other studies, DSWI was defined as mediastinitis with the need for wound debridement. Ratios in these studies ranged from $0.2 \%$ to $3.4 \%$. $^{2,3,8-14}$ Other studies used a broader definition that included sternal osteomyelitis. In these studies, infection risks ranged from $1.2 \%$ to $6.8 \% .{ }^{15-17}$ Our study defined infections by Centers for Disease Control and Prevention criteria, which are parallel to the latter group since only 32 of the 42 DSWIs in our study required reoperation. Another reason for this apparent high risk is the prospective design of the study, which probably resulted in more accurate surveillance. It is noteworthy that retrospective series* usually found a lower risk of DSWI than seen in prospective series ${ }^{6,12,16,17}(0.2 \%$ to $3.4 \%$ and $0.6 \%$ to $6.8 \%$, respectively).

This study was performed for a limited period, and an outbreak in one particular unit could have biased the results. Monthly risks of DSWI were similar, however, and the multicenter design of the study probably controlled for this potential bias. Because patients in this study were not systematically surveyed beyond poststernotomy day 8 , one could question the accuracy of detection of DSWI, for which median onset was postoperative day 12 . Patients who acquire serious SWI, however, in most cases return to the cardiac surgical unit for treatment. In addition, postoperative stay in cardiac surgical units was notably long (median 11 days for noninfected patients). It is therefore unlikely that many DSWIs have been missed.

Our results confirm those of previous studies that identified obesity and reoperation as risk factors for DSWI.* The prolonged use of inotropic agents was another risk factor for DSWI. Sizable doses were required to meet this criterion to select patients with unstable hemodynamic status. Inotropic support has never been recorded in other studies, but other closely related parameters, such as use of an intraaortic balloon pump, prolonged mechanical ventilation, or prolonged stay in the ICU, have previously been identified as risk factors for DSWI. ${ }^{3,6,10,14}$ The use of inotropic agents may reflect a prolonged stay in ICU and exposure of the mediastinal area to remote site infections. For unstable hemodynamic condition by itself to be a risk factor for DSWI is biologically plausible, however, because it decreases wound perfusion and alters local immune reactions. In addition, the vast majority of organisms isolated from DSWIs were grampositive cocci. Gram-negative microorganisms isolated in DSWIs usually originate from a remote source in the postoperative period, whereas grampositive cocci are likely to be inoculated from the patient's endogenous flora or the environment during the operation. ${ }^{1}$ We assume that impaired host defenses in hemodynamically unstable patients can-

*References 2, 3, 10, 11, 14, 15, 18, and 19.

${ }^{*}$ References 2, 3, 6, 10, 15, and 16 . 
not eliminate the perioperative inoculum, leading to subsequent DSWI.

CABG, especially bilateral ITA grafting, was a risk factor for DSWI. The association of DSWI with bilateral ITA grafting has been controversial. Some studies demonstrated a significant risk, ${ }^{6,9,10}$ others an increased although nonsignificant risk, ${ }^{2,7}$ and still another no risk at all. ${ }^{8}$ Our data confirm that bilateral ITA grafting is a major and consistent risk factor for DSWI. As previously suggested, this high risk was not explained by other parameters possibly related to this surgical procedure, such as secondary reoperation. This suggests that bilateral ITA grafting is in itself responsible for DSWI. The pathophysiology is well demonstrated in animal studies. ${ }^{19}$ Because the ITAs provide the major blood supply to the sternum, there is a potential risk for devascularization of the anterior sternum and subsequent SWI as a result of ischemic local conditions.

Obesity was the only independent preoperative risk factor for DSWI after TCABG. Although not significant in this group of patients, entering the cardiac surgical unit from an ICU appeared to be a major risk factor after bilateral ITA grafting. Cardiac ischemic accidents before operation were not recorded in our study, but we assume that transfer from an ICU may reflect recent occurrence of such an event. Obesity is not amenable to correction before urgent operation, but bilateral ITA grafting could sometimes be delayed in patients referred from an ICU.

Bilateral ITA grafting has been demonstrated to improve long-term graft patency, and it probably prolongs survival of the patient. ${ }^{8,20}$ This type of operation is therefore often proposed for young patients, as shown in our study. Unfortunately, these patients often exhibit other risk factors for infection. The benefits of bilateral ITA grafting clearly outweigh the risks of DSWI, but this procedure should be carefully considered in patients with preoperative risk factors. Moreover, in one series without increased risk for DSWI after bilateral ITA grafting, authors suggested that careful selection of patients was one reason for the low infection risk. ${ }^{7}$ A preoperative risk score could help to estimate the risk of postoperative DSWI and could facilitate special attention to perioperative and postoperative periods in such patients.

One unit exhibited a higher risk of DSWI. This observation must be considered cautiously because a cluster of infections could have occurred during the short study period. Further analysis showed that duration of operation, after adjustment for variation in operative times across units and for surgical procedures, was the major risk factor for DSWI. In absolute terms, however, duration of operation in this unit was in the low range compared with the other nine units. We suggest that duration of operation reflects other factors, such as operating room policies or asepsis in the operating room. ${ }^{21}$ Unfortunately, these factors were not recorded and require further investigation.

Multicenter studies have determined reliable risk factors for surgical wound infections and help surgeons to compare rates across units. ${ }^{22}$ The National Nosocomial Infections Surveillance (NNIS) System developed a composite risk index, which is a good predictor of surgical wound infection across a broad range of operations, including cardiac operations. ${ }^{21}$ The NNIS index does not include such important variables in cardiac surgery, however, as obesity, type of procedure, or reoperation. In addition, virtually all cardiac procedures are defined as clean in the surgical wound class, one of the three variables used to stratify surgical wound infections in the NNIS index. Furthermore, the American Society of Anesthesiologists score and operative time, the two other variables used in the NNIS index, were not risk factors in our study. We suggest that a unique index should be created for cardiac operations, with several purposes: to compare the incidence of DSWI after adjustment for confounding variables, to assess before operation risks for subsequent DSWI, and also to determine unit-specific risk factors pertaining to increased risk of infection.

In conclusion, a multicenter approach is important to identify reliable risk factors for DSWI. Most risk factors are not amenable to intervention. Incidence could, however, be reduced by careful assessment of indications for surgical procedures, especially bilateral ITA grafting, and by monitoring operative procedures in units where duration of operation is found to be a risk factor.

We are indebted to the staff of the cardiac surgical units and microbiology laboratories who participated in this study and to J. E. McGowan (Rollins School of Public Health, Emory University, Atlanta, Ga.) for review of the manuscript.

\section{REFERENCES}

1. Sarr MG, Gott VL, Townsend TR. Mediastinal infection after sternotomy. Ann Thorac Surg 1984;38:415-23.

2. Loop FD, Lytle BW, Cosgrove DM, et al. Sternal wound complications after isolated coronary bypass grafting: early 
and late mortality, morbidity and cost of care. Ann Thorac Surg 1990;49:179-87.

3. Grossi EA, Culliford AT, Krieger KH, et al. A survey of 77 major infectious complications of median sternotomy: a review of 7,949 consecutive operative procedures. Ann Thorac Surg 1985;40:214-21.

4. Keats AS. The ASA classification of physical status-a recapitulation. Anesthesiology 1978;49:233-36.

5. Garner JS, Jarvis WR, Emori TG, Horan TC, Hughes JM. CDC definitions for nosocomial infections 1988. Am J Infect Control 1988;16:128-40.

6. Kouchoukos NT, Wareing TH, Murphy SF, Pelate C, Marshall WG. Risks of bilateral internal mammary artery grafting. Ann Thorac Surg 1990;49:210-9.

7. He GW, Ryan WH, Acuff, TE et al. Risk factors for operative mortality and sternal wound infection in bilateral internal mammary artery grafting. J Thorac Cardiovasc Surg 1994; 107:196-202

8. Galbut DL, Traad EA, Dorman MJ, et al. Seventeen-year experience with bilateral internal mammary artery grafts. Ann Thorac Surg 1990;49:195-201.

9. Grossi EA, Esposito R, Harris LJ, et al. Sternal wound infection and use of internal mammary artery grafts. $J$ Thorac Cardiovasc Surg 1991;102:342-7.

10. Hazelrigg SR, Wellons HA, Schneider JA, Kolm P. Wound complications after median sternotomy. J Thorac Cardiovasc Surg 1989;98:1096-9.

11. Bor DH, Rose RM, Modlin JF, Weintraub R, Friedland GH. Mediastinitis after cardiac surgery. Rev Infect Dis 1983;5: 885- 97.

12. Breyer RH, Mills SA, Hudspeth AS, Johnston FR, Cordell AR. A prospective study of sternal wound complications. Ann Thorac Surg 1984;37:412-5.

13. Ko W, Lazenby WD, Zelano JA, Isom OW, Krieger KH. Effects of shaving methods and intraoperative irrigation on suppurative mediastinitis after bypass operations. Ann Thorac Surg 1992;53:301-5.

14. Newman LS, Szczukowski LC, Bain RP, Perlino CA. Suppurative mediastinitis after open-heart surgery. Chest $1988 ; 94$ : 546-53.

15. Ottino G, De Paulis R, Pansini S, et al. Major sternal wound infection after open-heart surgery: a multivariate analysis of risk factors in 2,579 consecutive operative procedures. Ann Thorac Surg 1987;44:173-9.

16. Nagachinta T, Stephens M, Reitz B, Polk BF. Risk factors for surgical-wound infection following cardiac surgery. J Infect Dis $1987 ; 156: 967-73$.
17. Sellick JA, Stelmach M, Mylotte JM. Surveillance of surgical wound infections following open-heart surgery. Infect Control Hosp Epidemiol 1991;12:591-96.

18. Demmy TL, Park SB, Liebler GA, et al. Recent experience with major sternal wound infections. Ann Thorac Surg 1990;49:458-62.

19. Seyfer AE, Shriver CD, Miller TR, Graeber GM. Sternal blood flow after median sternotomy and mobilization of the internal mammary arteries. Surgery 1988;104:899-904.

20. Fiore AC, Naumheim KS, Dean P, et al. Results of internal thoracic artery grafting over 15 years: single vs double grafts. Ann Thorac Surg 1990;49:202-9.

21. Culver DH, Horan TC, Gaynes RP, et al. Surgical wound infection by wound class, operative procedure, and patient risk index. Am J Med 1991;91(Suppl 3B):152S-7S.

22. Consensus paper on the surveillance of surgical wound infections. Infect Control Hosp Epidemiol 1992;13:599-605.

\section{The Parisian Mediastinitis Study Group}

F. Brunet, MD, A. Brusset, MD, P. Squara, MD (Clinique A. Paré, Neuilly sur Seine); Y. Philip, MD (Hôpital Bichat, Paris); B. Abry, MD, A. Roy, MD (Clinique du Bois de Verrières, Antony); C. Amrein, MD, R. Guillemain, MD (Hôpital Broussais, Paris); C. Dubois, MD, P. de Lentdecker, MD (Hôpital Foch, Suresnes); L. Aberkane, MD (Hôpital Henri-Mondor, Créteil); R. Ouaknine, MD (Hôpital Laennec, Paris); F. Tronc, MD (Hôpital Lariboisière, Paris); J. Bruniaux, MD, J. P. Duffet, MD, V. Yakar, RN (Hôpital Marie-Lannelongue, le Plessis Robinson); C. Lamer, MD, and J. Pétrie, MD (Clinique de la Porte de Choisy, Paris).

Coordination: J. C. Lucet, MD, MPH, ${ }^{a}$ D. Batisse, $\mathrm{MD},{ }^{\mathrm{a}}$ C. Dumartin, MD, ${ }^{a}$ M. J. Laisné, MD, ${ }^{\mathrm{b}} \mathrm{J}$. Lortholary, $\mathrm{MD},{ }^{\mathrm{a}}$ and $\mathrm{G}$. Brücker, $\mathrm{MD}^{\mathrm{a}}$; Service Epidémiologie, Hygiène et Prévention ${ }^{\mathrm{a}}$ and Comité Central de Lutte contre l'Infection Nosocomiale, Assistance Publique-Hopitaux de Paris, 3, Avenue Victoria, 75004 Paris, France. 